\title{
Improved redox homeostasis owing to the up-regulation of one-carbon metabolism and related pathways is crucial for yeast heterosis at high temperature
}

\author{
Liang Song, ${ }^{1,2,3}$ Jun-Yan Shi, ${ }^{1,2,3}$ Shou-Fu Duan, ${ }^{1}$ Da-Yong Han, ${ }^{1,2}$ Kuan Li, ${ }^{1}$ \\ Ri-Peng Zhang, ${ }^{1,2}$ Peng-Yu He, ${ }^{1,2}$ Pei-jie Han, ${ }^{1}$ Qi-Ming Wang, ${ }^{1}$ and Feng-Yan Bai ${ }^{1,2}$ \\ ${ }^{1}$ State Key Laboratory of Mycology, Institute of Microbiology, Chinese Academy of Sciences, Beijing 100101, China; ${ }^{2}$ College \\ of Life Sciences, University of Chinese Academy of Sciences, Beijing 100049, China
}

\begin{abstract}
Heterosis or hybrid vigor is a common phenomenon in plants and animals; however, the molecular mechanisms underlying heterosis remain elusive, despite extensive studies on the phenomenon for more than a century. Here we constructed a large collection of F1 hybrids of Saccharomyces cerevisiae by spore-to-spore mating between homozygous wild strains of the species with different genetic distances and compared growth performance of the F1 hybrids with their parents. We found that heterosis was prevalent in the $\mathrm{F} 1$ hybrids at $40^{\circ} \mathrm{C}$. A hump-shaped relationship between heterosis and parental genetic distance was observed. We then analyzed transcriptomes of selected heterotic and depressed F1 hybrids and their parents growing at $40^{\circ} \mathrm{C}$ and found that genes associated with one-carbon metabolism and related pathways were generally up-regulated in the heterotic F1 hybrids, leading to improved cellular redox homeostasis at high temperature. Consistently, genes related with DNA repair, stress responses, and ion homeostasis were generally down-regulated in the heterotic F1 hybrids. Furthermore, genes associated with protein quality control systems were also generally down-regulated in the heterotic F1 hybrids, suggesting a lower level of protein turnover and thus higher energy use efficiency in these strains. In contrast, the depressed F1 hybrids, which were limited in number and mostly shared a common aneuploid parental strain, showed a largely opposite gene expression pattern to the heterotic F1 hybrids. We provide new insights into molecular mechanisms underlying heterosis and thermotolerance of yeast and new clues for a better understanding of the molecular basis of heterosis in plants and animals.
\end{abstract}

[Supplemental material is available for this article.]

Hybrid vigor, or heterosis, refers to the phenomenon that hybrid offspring are more vigorous than their genetically different homozygous parents. Hybrid vigor was first described in plants by Charles Darwin in 1876, who observed that cross-pollinated plants usually show better performances in height, weight, and fertility than their self-pollinated counterparts (Darwin 1876). This phenomenon was rediscovered in maize in 1908 (Shull 1908), and the term "heterosis" was introduced by Shull (1914) for this concept. Since then, heterosis has been widely observed in plants and animals and extensively exploited in agriculture, resulting in a great and constant increase in agricultural productivity worldwide (Lippman et al. 2008; Schnable and Springer 2013; Hochholdinger and Baldauf 2018).

The question of why hybrids show better performances in different traits has fascinated scientists for more than a century. Despite extensive studies on the question that have been performed since the early days of Darwin, little consensus has yet been reached about the genetic basis and molecular mechanisms of heterosis (Hochholdinger and Hoecker 2007; Lippman and Zamir 2007; Hochholdinger and Baldauf 2018; Govindaraju 2019). Different genetic hypotheses have been proposed to ex-

\footnotetext{
${ }^{3}$ These authors contributed equally to this work. Corresponding author: baify@im.ac.cn

Article published online before print. Article, supplemental material, and publication date are at https://www.genome.org/cgi/doi/10.1101/gr.262055.120.
}

plain the phenomenon, including the three classic models: dominance (Davenport 1908; Bruce 1910; Jones 1917), overdominance (Shull 1911; East 1936), and epistasis (Richey 1942; Powers 1944). According to the dominance model, the complementation of slightly deleterious recessive alleles in heterozygotes leads to heterosis (Shull 1908; Charlesworth and Willis 2009). The overdominance model suggests that interactions occur between the alleles in the progeny and result in better performance than either homozygous parents (Shull 1911; Li et al. 2008; Chen 2013). The epistasis hypothesis, however, believes that interactions between nonallelic genes in hybrids result in heterosis (Yu et al. 1997; Fiévet et al. 2010; Hochholdinger and Baldauf 2018). There are experimental evidences that support each of these hypotheses. However, none of the classic models that were proposed before the era of molecular biology can fully explain the molecular mechanism of heterosis (Fiévet et al. 2018; Hochholdinger and Baldauf 2018).

In recent years, genomics, transcriptomics, proteomics, and systemic tools have been used in the studies of heterosis, resulting in improved understanding of heterosis at the molecular level (Hochholdinger and Hoecker 2007; Birchler et al. 2010; Schnable

(C) 2021 Song et al. This article is distributed exclusively by Cold Spring Harbor Laboratory Press for the first six months after the full-issue publication date (see https://genome.cshlp.org/site/misc/terms.xhtml). After six months, it is available under a Creative Commons License (Attribution-NonCommercial 4.0 International), as described at http://creativecommons.org/licenses/by-nc/4.0/. 
and Springer 2013; Fiévet et al. 2018; Fujimoto et al. 2018; Hochholdinger and Baldauf 2018; Vasseur et al. 2019). The contribution of different gene expression models to heterosis has been observed. These models include nonadditive or allele-specific gene expression, single-gene overdominance or underdominance, and single-parent expression complementation (Hoecker et al. 2008; Li et al. 2008; Wei et al. 2009; Guo et al. 2010; Krieger et al. 2010; Riddle et al. 2010; Paschold et al. 2012; Baldauf et al. 2018; Gonzalez-Bayon et al. 2019; Zhao et al. 2019). However, no consensus set or enriched functional categories related to heterosis have been identified (Fujimoto et al. 2018; Hochholdinger and Baldauf 2018). Other studies ascribe heterosis to a systemic property resulting from nonlinear concave genotype-phenotype relationships of living systems (Fiévet et al. 2018; Vasseur et al. 2019). Aiming to unify the theories for heterosis, a metabolic or energy-use efficiency hypothesis has been proposed (Ginn 2010, 2017; Goff 2011). Previous studies have shown that inbred organisms usually have increased rates of protein turnover relative to noninbred organisms (Hawkins et al. 1986; Hedgecock et al. 1996; Bayne 2004). Based on theoretical biophysics calculations, Ginn $(2010,2017)$ postulated that the higher levels of protein turnover among inbred organisms can be attributed to the accumulations of misfolded and aggregated proteins that require degradation by the inbred organisms' protein quality control systems. Both protein synthesis and degradation are energy-consuming processes; inbred organisms must consume more energy to sustain a given biomass and are thus less "metabolically efficient." Goff (2011) speculated that hybrids achieve greater energy efficiency via selective protein synthesis and metabolism. The model describes that cells distinguish between parental alleles based on the relative stability of the encoded proteins and use allele-specific gene expression to conserve energy and promote growth. Outcrossing provides more opportunity for allele selection and thereby increases the potential for enhanced vigor (Goff 2011). However, solid molecular evidence for the energy-use efficiency hypothesis has not been shown.

With the advantages of clear genetic and genomic background and being amenable to large-scale laboratory experiments, Saccharomyces cerevisiae and related yeast species have been used in the study on heterosis (Steinmetz et al. 2002; Marullo et al. 2006; Naumov et al. 2006; Sinha et al. 2006; Timberlake et al. 2011; Shapira et al. 2014; Blein-Nicolas et al. 2015; Shapira and David 2016; Bernardes et al. 2017; Herbst et al. 2017; Martí-Raga et al. 2017; Fiévet et al. 2018; Jansen et al. 2018). However, it is also difficult to find consensus from these studies about the mechanism of heterosis. Steinmetz et al. (2002) and Sinha et al. (2006) showed that both dominance and epistasis at three quantitative trait genes-MKT1, END3, and $\mathrm{RHO} 2$ - contributed to growth heterosis at high temperatures in some yeast hybrids but were not conserved in others. Plech et al. (2014) reported that heterosis was prevalent among domesticated but not wild strains of $S$. cerevisiae. Based on the study on an interspecific hybrid between $S$. cerevisiae and Saccharomyces paradoxus strains, Herbst et al. (2017) ascribed heterosis to the impairment of growth-limiting pathways caused by regulatory incompatibility in hybrids. According to this hypothesis, the regulatory mechanisms related to growth-rate-limiting and safe-guard processes in hybrids were perturbed because of genomic incompatibility, allowing hybrid cells to grow faster and finally leading to heterosis (Bar-Zvi et al. 2017; Herbst et al. 2017).

Our recent population genomic study on $S$. cerevisiae showed a hallmark difference in heterozygosity between the wild and domesticated populations of the species. Wild isolates are exclusively homozygous, whereas domesticated isolates are generally heterozygous (Duan et al. 2018). The domesticated populations appear to have originated from ancestors formed by outcrossing between diverse wild isolates, and heterosis is probably responsible for the improved high temperature tolerance ability of domesticated isolates (Duan et al. 2018). The goal of this study is to check if heterosis is prevalent in wild $S$. cerevisiae at high temperature, to investigate correlation of heterosis with genetic distances, and to illuminate molecular mechanisms underlying thermotolerant heterosis of yeast. We provide new insights into molecular mechanisms underlying heterosis and thermotolerance of yeast and new clues for a better understanding of the molecular basis of heterosis in plants and animals.

\section{Results}

Wild yeast hybrids showed growth heterosis at high temperature

A total of 53 wild strains of S. cerevisiae (Supplemental Table S1) were selected from different wild lineages of the species recognized in our previous studies (Wang et al. 2012; Duan et al. 2018). These strains represent the largest genetic diversity of the wild population of $S$. cerevisiae documented so far (Duan et al. 2018). We generated 641 F1 hybrids without any genetic marker by sporeto-spore mating between pairs of the wild $S$. cerevisiae strains with genetic distance ranging from $0.323 \times 10^{-3}$ to $15.337 \times 10^{-3}$ (Supplemental Table S1). The F1 hybrids showing increased fitness (i.e., heterosis) and decreased fitness (i.e., outbreeding depression) were determined based on the fitness variables including maximum growth rate and growth efficiency compared with their parents at $30^{\circ} \mathrm{C}$ and $40^{\circ} \mathrm{C}$, respectively. The $\mathrm{F} 1$ hybrids with different degrees of heterosis were then identified. If a hybrid shows a fitness value being significantly higher than the average value of its parents (mid-parent value [MPV]) or than the fitness value of the better parent, it is defined as a hybrid with mid-parent heterosis (MPH) or better-parent heterosis (BPH) (Zörgö et al. 2012). If the fitness of a F1 hybrid is significantly lower than that of the worst parent, the hybrid is classified in the group of outbreeding depression or worst parent heterosis (WPH), as defined in Zörgö et al. (2012). We found that at $30^{\circ} \mathrm{C}, 39.7 \%$ and $27.4 \%$ of the $\mathrm{F} 1$ hybrids showed MPH and $\mathrm{BPH}$, respectively, in maximum growth rate, and $64.0 \%$ and $34.1 \%$ showed $\mathrm{MPH}$ and $\mathrm{BPH}$, respectively, in growth efficiency (Supplemental Fig. S1A). However, the growth difference between the F1 hybrids and their parents was generally unremarkable, and the mean fitness of the F1 hybrids did not deviate from the MPV significantly in maximum growth rate (MannWhitney $U$ test, $P=0.153)$ and slightly deviated from MPV $(P=$ 0.007 ) in growth efficiency (Supplemental Fig. S1B). In contrast, the $\mathrm{F} 1$ hybrids showed evident heterosis at $40^{\circ} \mathrm{C}$. In average, the fitness of the F1 hybrids was significantly higher than the MPV in both growth rate and efficiency (Mann-Whitney $U$ test, $P<$ 0.001) (Fig. 1A; Supplemental Table S1). A total of $95.8 \%$ and $75.9 \%$ of the $\mathrm{F} 1$ hybrids showed $\mathrm{MPH}$ and $\mathrm{BPH}$, respectively, in growth rate, and $92.4 \%$ and $69.5 \%$ of the F1 hybrids showed $\mathrm{MPH}$ and $\mathrm{BPH}$, respectively, in growth efficiency (Fig. 1B). Only $16(2.5 \%)$ and $14(2.2 \%)$ out of the $641 \mathrm{~F} 1$ hybrids tested showed outbreeding depression in growth rate and efficiency, respectively (Fig. 1B). Notably, $81.3 \%(13 / 16)$ and $57.1 \%(8 / 14)$ of the depressed F1 hybrids in growth rate and efficiency, respectively, share a common parental strain BJ22 which is aneuploid (Duan et al. 2018). These results show that heterosis is prevalent in F1 hybrids of wild $S$. cerevisiae strains at high temperature. 

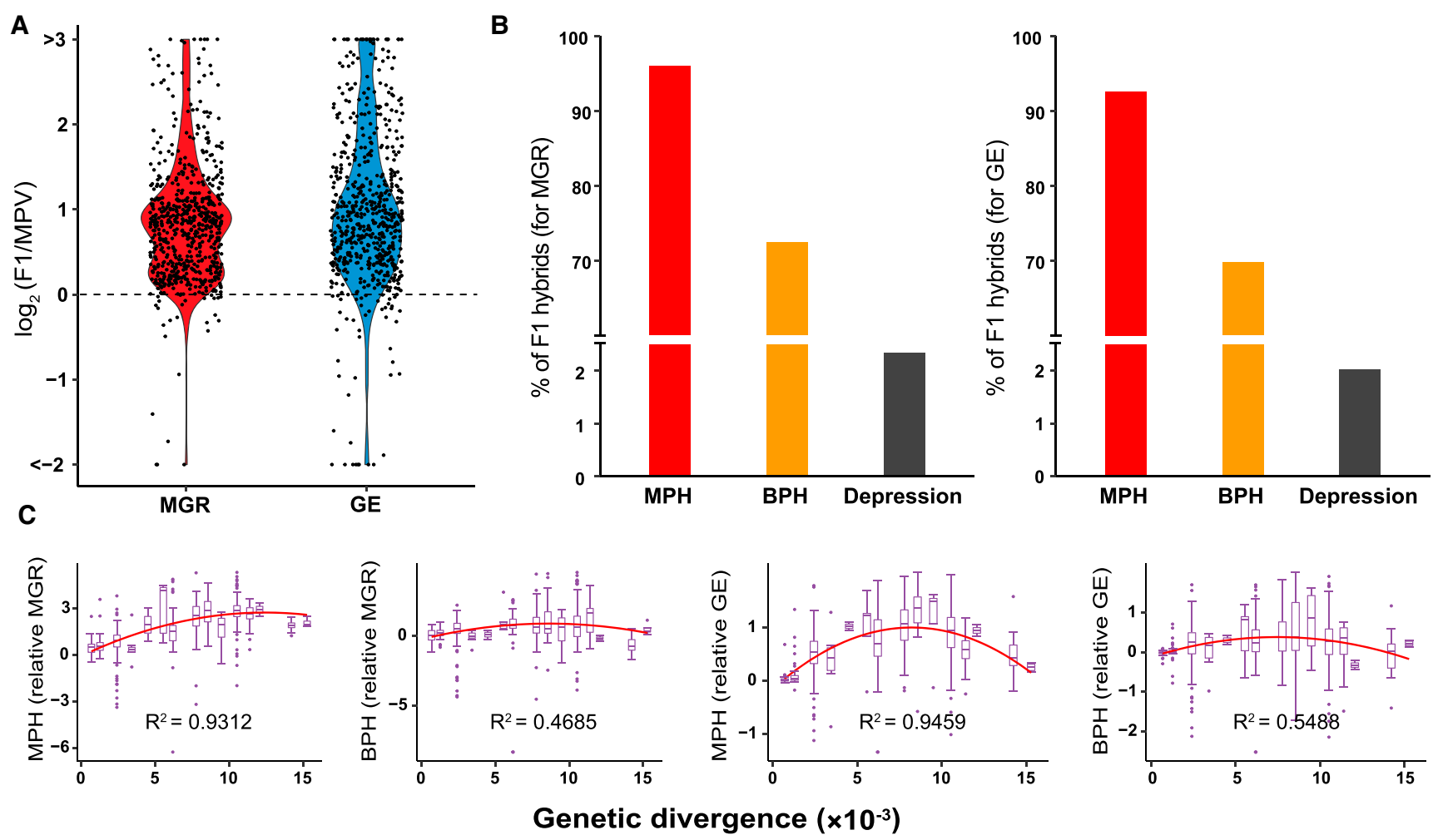

Figure 1. Heterosis of $\mathrm{F} 1$ hybrids of wild $\mathrm{S}$. cerevisiae, and correlation between heterosis and the genetic distance of parental strains at $40^{\circ} \mathrm{C}$. $(A)$ Maximum growth rate (MGR) and growth efficiency (GE) of F1 hybrids relative to the average values of their parents (mid-parent value [MPV]). (B) Proportions of $\mathrm{F} 1$ hybrids showing mid-parent heterosis (MPH), better-parent heterosis (BPH), and outbreeding depression. (C) Correlation between genetic distances of parental strains and growth performance of $F 1$ hybrids relative to the MPV (MPH) or the better parent value (BPH) in terms of MGR or GE.

The genetic distances between the parental strains (Supplemental Table S1) were calculated based on their genome sequences determined previously (Duan et al. 2018). The correlation between the degree of heterosis and the parental genetic distance was analyzed using linear and nonlinear models (Wei and Zhang 2018; Vasseur et al. 2019). We found that the quadratic model was favored in explaining the data observed (Supplemental Table S2). We found a hump-shaped relationship between MPH and parental genetic distance in both growth rate $\left(R^{2}=0.9312, P<0.05\right)$ and efficiency $\left(R^{2}=0.9459, P<0.05\right)$. A relatively weaker hump-shaped relationship between $\mathrm{BPH}$ and parental genetic distance was also observed in growth rate $\left(R^{2}=0.4685, P<0.05\right)$ and efficiency $\left(R^{2}=0.5488, P<0.05\right)$ (Fig. 1C). The optimal mating distances were estimated to be $7.42 \times 10^{-3}$ to $10.56 \times 10^{-3}$ for different types of heterosis (Supplemental Table S2).

\section{Additive and nonadditive gene expression in F1 hybrids}

To uncover the molecular mechanisms of heterosis of wild yeast at high temperature, we compared the gene expression profiles of selected F1 hybrids and their parents in the logarithmic growth phase at $40^{\circ} \mathrm{C}$ using RNA sequencing (RNA-seq) analysis. The strains were selected based on the considerations that the hybrids showed clear growth performance differences from their parents and that the parental strains represented different lineages with different genetic distances. A total of 94 strains, including 59 F1 hybrids and their parents (34 strains), were used in the RNA-seq analysis (Supplemental Table S3). Among the F1 hybrids, 50 showed BPH and the other nine showed outbreeding depression in both growth rate and efficiency, except two of the depressed hybrids showed outbreeding depression only in growth rate (Supplemental Table S3). We obtained high-quality RNA-seq data from two biological repeats for each strain (Supplemental Table S4). The reliability of the RNA-seq data was validated by quantitative real-time PCR (qRT-PCR) analysis. Eighteen genes were randomly selected from the actively expressed genes, and their expression levels in 18 of the RNA samples subjected to RNA-seq analysis were determined by qRT-PCR analysis (Supplemental Table S5). A strong correlation between the expression levels of the 18 genes determined by RNA-seq and qRT-PCR was observed in each sample (Supplemental Fig. S2).

The expression of a gene in a F1 hybrid is expected to occur in one of the two modes: additive and nonadditive. The additive expression occurs when the expression level of a gene in a F1 hybrid is equal to the average expression level of the gene in its parents (MPV), indicating the same expression levels of the alleles in the hybrid and the corresponding parents. Nonadditive expression occurs when the expression level of a gene in a F1 hybrid significantly deviates from the MPV, suggesting altered expression levels of the corresponding alleles in the hybrid (Hochholdinger and Hoecker 2007; Wei et al. 2009). A correlation of nonadditive gene expression with heterosis has been observed in plant (Li et al. 2009; Birchler et al. 2010; Riddle et al. 2010; Zhao et al. 2019). We found that additive expression was prevalent in the F1 hybrids of $S$. cerevisiae analyzed (Fig. 2A). Only a limited number $(0-7.9 \%)$ of the expressed genes showed a nonadditive expression pattern in the F1 hybrids (Fig. 2A; Supplemental Table S6). However, we found a clear difference in the numbers and

\section{Genome Research}

www.genome.org 

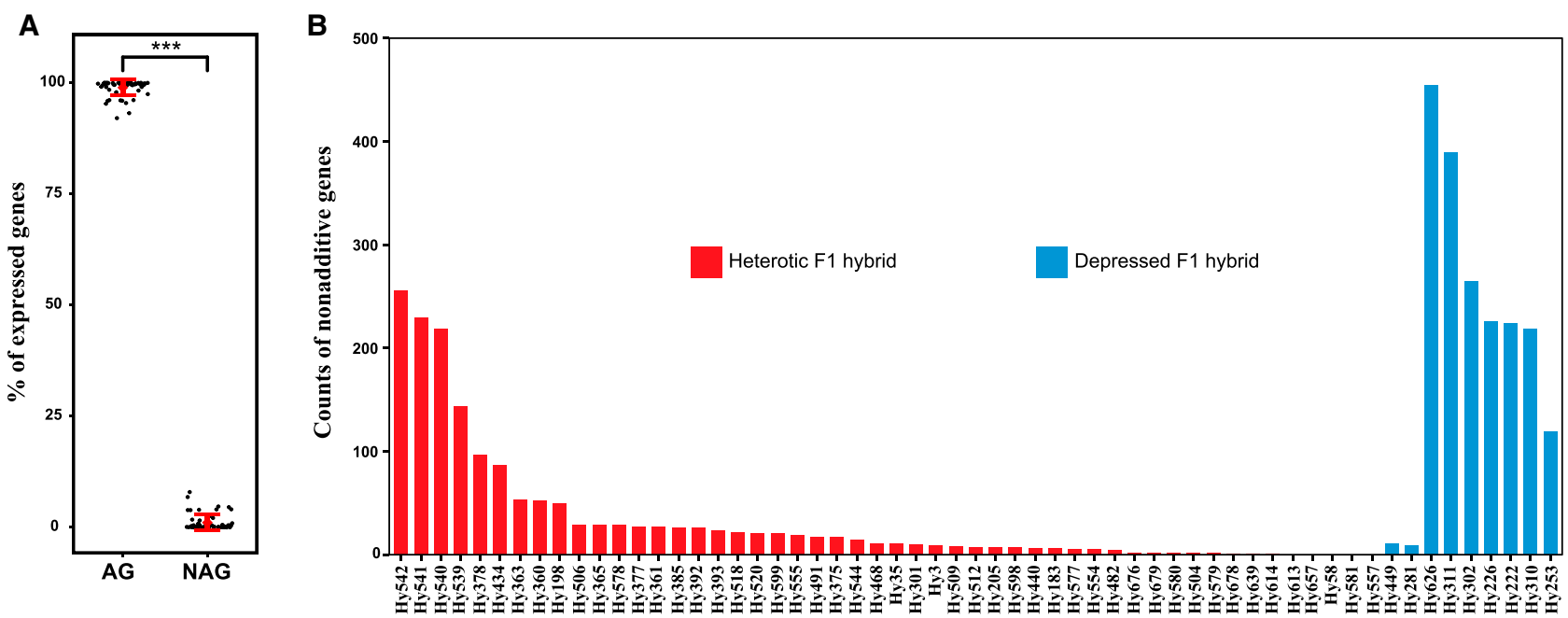

Figure 2. Gene expression variations of $F 1$ hybrids and their parents at $40^{\circ} \mathrm{C}$. (A) Proportions of additive genes (AGs) and nonadditive genes (NAGs) in every F1 hybrid. $\left.{ }^{* * *}\right) P<0.001$ (Mann-Whitney $U$ test). (B) Counts of nonadditive genes in every heterotic and depressed F1 hybrid.

proportions of nonadditive genes between the heterotic and depressed F1 hybrids (Fig. 2B), although the limited number of the depressed hybrids compared did not allow a convincing statistical comparison.

We then compared the expression levels of the nonadditive genes relative to the MPV. The heatmap showed that a considerable number of the nonadditive genes showed a largely opposite expression level between the heterotic and depressed F1 hybrids (Supplemental Fig. S3A). Statistical analysis showed that the number of the nonadditive genes with expression levels below the MPV was much higher than that of the nonadditive genes with expression levels above the MPV in the heterotic F1 hybrids. However, an opposite trend was observed in the depressed F1 hybrids (Supplemental Fig. S3B). The result implies possible roles of nonadditive genes in the manifestation of heterosis or outbreeding depression in S. cerevisiae.

\section{Nonadditive genes are enriched in specific pathways}

The nonadditive genes recognized from all the F1 hybrids used in RNA-seq analysis were then subjected to correlation analysis using the weighted gene coexpression network analysis (WGCNA) tool (Langfelder and Horvath 2008). Briefly, significantly coexpressed nonadditive genes were clustered in separate modules. The genes in the modules with expression levels significantly correlated with growth rate or efficiency were selected for further analyses (Supplemental Fig. S4). A total of 523 coexpressed nonadditive genes with expression levels significantly correlated with the fitness of the hybrids $(R \geq 0.5$ or $\leq-0.5, P<0.05)$ were identified (Supplemental Table S7). The nonadditive genes in the heterotic F1 hybrids were clustered into two major groups (I and II) with expression levels generally lower (down-regulated) and higher (upregulated) than the MPV, respectively (Fig. 3A). A largely opposite expression pattern of these nonadditive genes was observed in the depressed F1 hybrids. That is, the nonadditive genes that were upregulated in the heterotic F1 hybrids were generally down-regulated in the depressed F1 hybrids and vice versa (Fig. 3A).

The two groups of the nonadditive genes were respectively subjected to Gene Ontology (GO) enrichment analysis using the Metascape tool (Zhou et al. 2019). The terms resulting from GO analysis were then connected to form different enrichment networks based on quantitative measurements of the functional similarities of the terms (Huang et al. 2009). The group I nonadditive genes were significantly enriched in 18 GO terms $(P<0.01)$ (Fig. 3B; Supplemental Table S8A). The GO terms associated with protein quality control formed one main network (Fig. 3C). This network includes the GO terms of protein folding, cellular protein catabolic process, response to stress, and regulation of protein stability. The GO terms associated with cellular ion homeostasis, iron chelate transport, and ion transmembrane transport formed the second network. The GO terms of glutamine family amino acid biosynthetic process, which is associated with oxidative stress response (Altman et al. 2016), formed the third network, together with GO terms of cellular aldehyde metabolic, lactate metabolic, and antibiotic catabolic processes (including response to toxic substance) (Fig. 3C). The genes associated with DNA repair in this group, including RAD51, RAD54, and RDH54 (Pâques and Haber 1999), were enriched in a separate GO term named heteroduplex formation (Fig. 3C; Supplemental Table S8A).

The group II nonadditive genes were significantly overrepresented in 17 GO terms $(P<0.05)$ (Fig. 3D; Supplemental Table $\mathrm{S} 8 \mathrm{~B})$. These GO terms were mainly clustered into two main networks (Fig. 3E). The GO terms associated with translation and ribosome biogenesis and assembly formed one major network. The GO terms of one-carbon (1C) metabolism, inosine monophosphate (IMP) metabolism, and methionine, serine, and aspartate family amino acid metabolism formed another main network (Fig. 3E).

The largely opposite expression levels of key nonadditive genes in the heterotic and depressed F1 hybrids are shown in Supplemental Figures S5 and S6. These genes are associated with protein quality control, DNA repair, or stress response (Supplemental Fig. S5) or with 1C, IMP, or serine and methionine metabolism (Supplemental Fig. S6). They were further classified into five categories based on their expression levels compared with those of their parents (Stupar et al. 2008; Schnable and Springer 2013). The expression levels of the nonadditive genes in group I were generally low parent (LP)-like (equal to the LP value) or below LP (lower than the LP value) in the heterotic F1 hybrids but high parent (HP)-like (equal to the HP value) or above HP (higher than the HP) in the depressed F1 hybrids (Fig. 4). The 
A

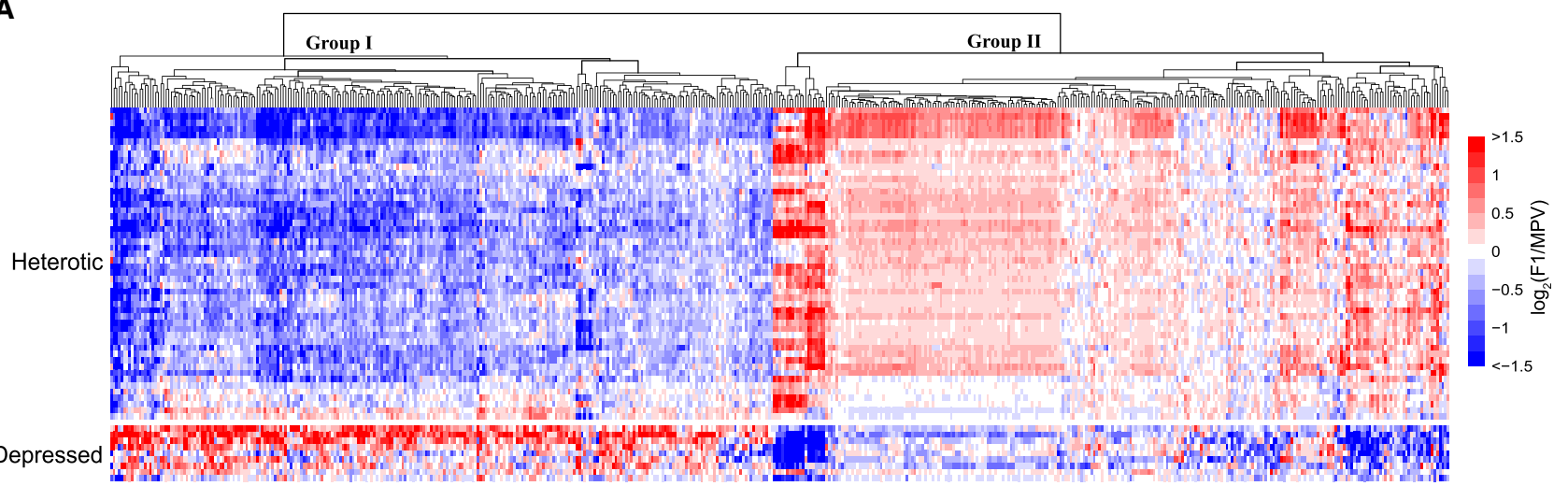

B

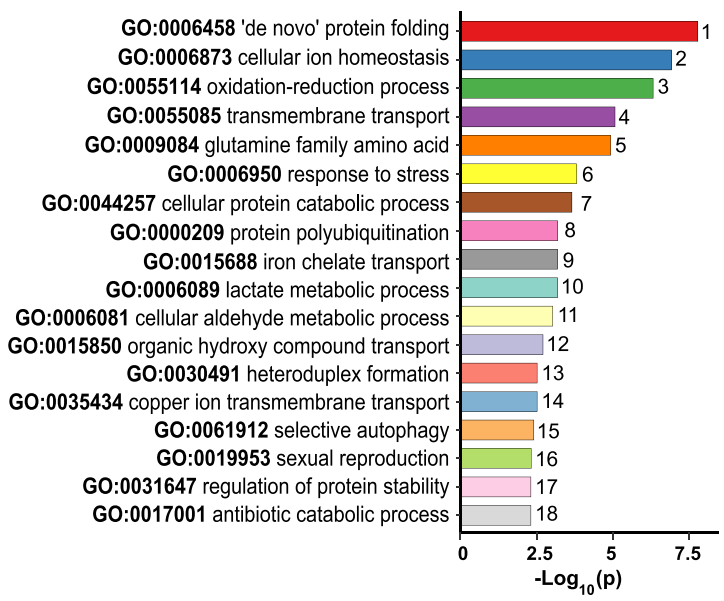

C

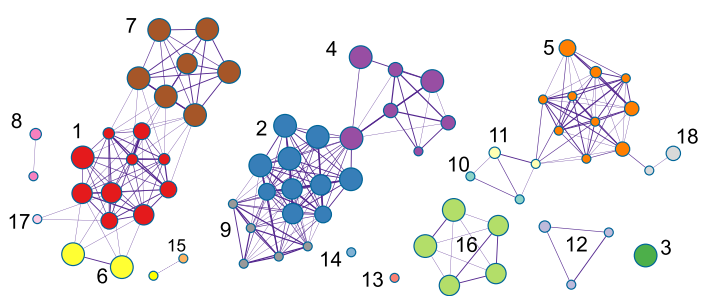

D

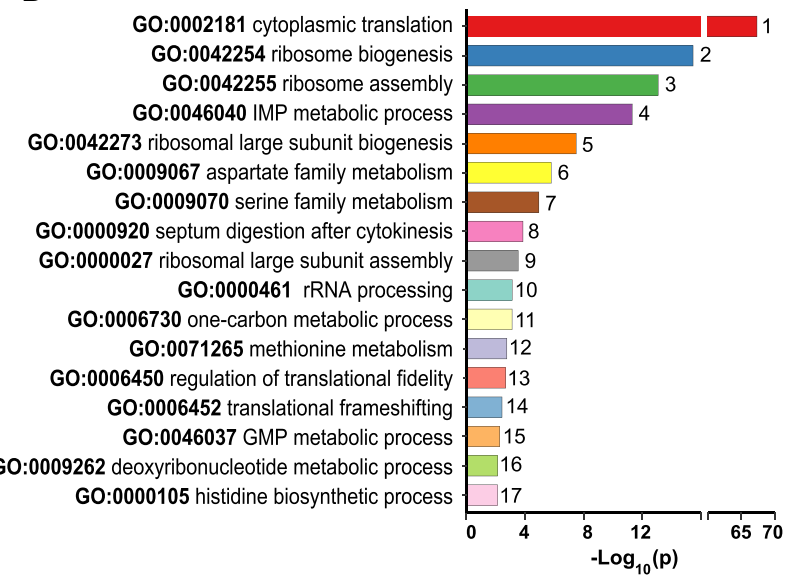

E

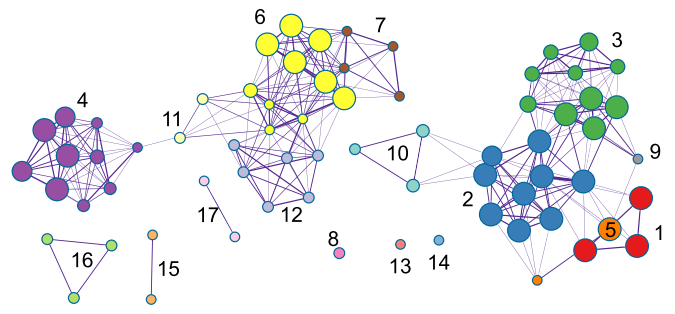

Figure 3. Functional categories of nonadditive genes in $\mathrm{F} 1$ hybrids of wild $\mathrm{S}$. cerevisiae. ( $A$ ) Heatmap shows the clustering of nonadditive genes based on their expression levels in each F1 hybrid relative to the average expression levels of the genes in the parents (MPV) of the hybrid according to the scale on the right, which depicts the values of $\log _{2}(F 1 / M P V)$. $(B, D)$ Nonredundant Gene Ontology $(G O)$ terms significantly enriched with the nonadditive genes in groups I and II, respectively. $P$-values represent statistical significance. $(C, E)$ Enrichment networks show the intra- and inter-cluster functional similarities of the enriched GO terms shown in $B$ and $D$, respectively. Enrichment networks are created by representing each enriched term as a node and connecting pairs of nodes with kappa similarities above 0.3 . Up to 10 terms represented by colored nodes are included per cluster. The color code is respectively the same with that in $B$ and $D$. The sizes of the nodes are proportional to the numbers of input genes falling into the terms.

expression levels of the nonadditive genes in group II were generally HP-like or above HP in the heterotic F1 hybrids but LP-like or below LP in the depressed F1 hybrids (Fig. 4).

\section{Lower ROS level in the cells of heterotic F1 hybrids}

High temperature usually triggers oxidative stress on the cells owing to the overproduction of reactive oxygen species (ROS) (Morano et al. 2012; Foyer and Noctor 2016). Genes related with oxidative-reduction processes and other stress responses were generally up-regulated in the depressed $\mathrm{F} 1$ hybrids but down-regulated in the heterotic F1 hybrids (Fig. 3A; Supplemental Fig. S5). Genes enriched in the glutamine metabolism process, which is crucial for cellular ROS homeostasis (Altman et al. 2016), were also up-regulated in the depressed F1 hybrids (Fig. 3A; Supplemental Fig. S5). These data suggest higher oxidative stress level in the depressed F1 hybrids. Consistently, the up-regulation of genes related with protein quality control and DNA repair systems (Fig. 3A; Supplemental Fig. S5) suggests more protein and DNA damage probably owing to a higher level of ROS in the depressed F1 hybrids. We therefore measured the ROS levels in the F1 hybrids and their parental strains when growing at $40^{\circ} \mathrm{C}$ (Supplemental Table S9). The average ROS levels in the heterotic F1 hybrids were significantly lower than the average ROS levels of their parents (MPV; $P=0.005)$. However, the average ROS level in the depressed F1 hybrids did not significantly differ from the MPV of

\section{Genome Research}

www.genome.org 


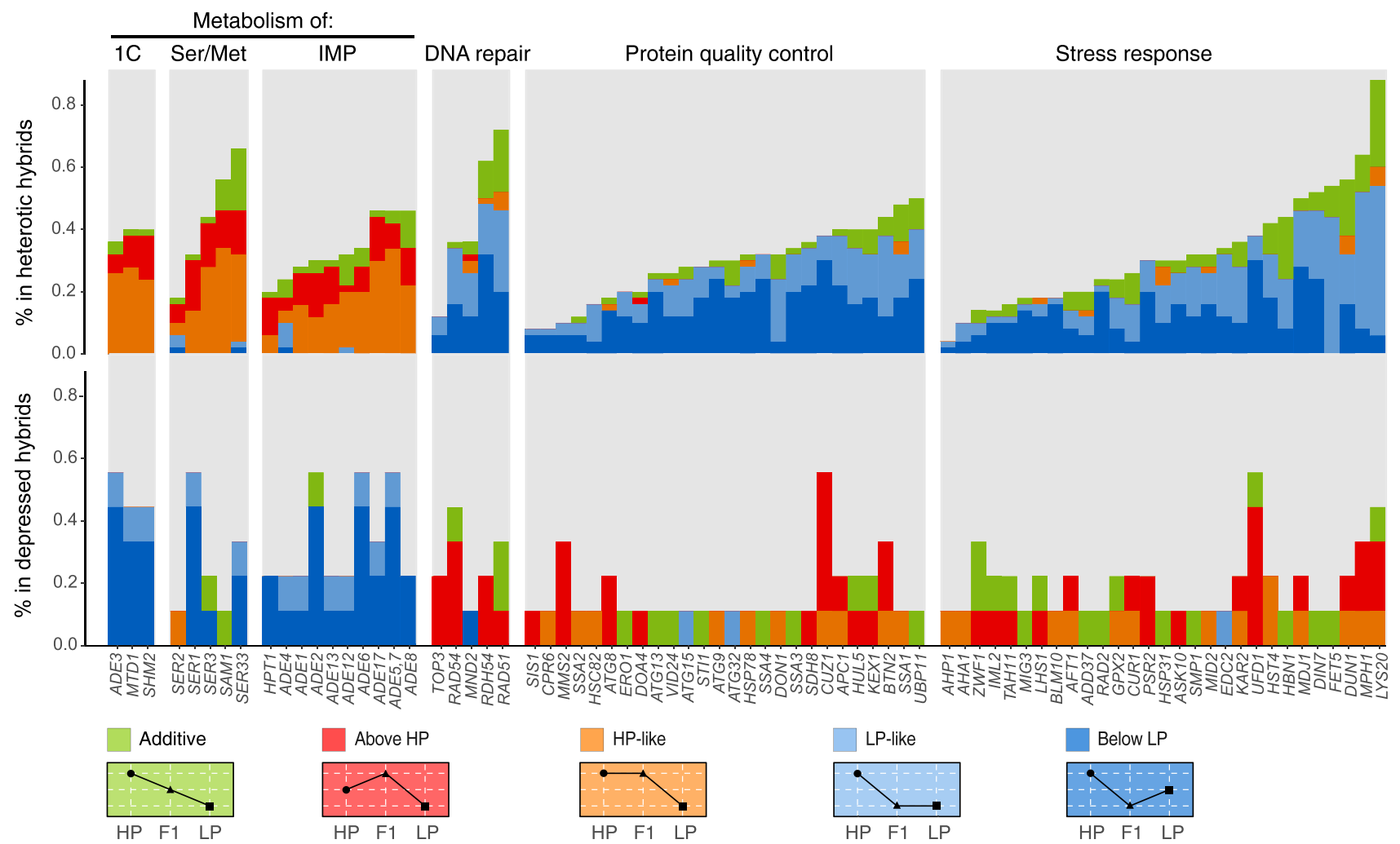

Figure 4. Proportions of key nonadditive genes showing different expression models in heterotic and depressed $\mathrm{F} 1$ hybrids of wild $\mathrm{S}$. cerevisiae growing at $40^{\circ} \mathrm{C}$. Five expression models are defined as illustrated at the bottom. (HP) High parent value; (LP) low parent value. The nonadditive genes are associated with six different functional categories as indicated. (1C) One-carbon; (Ser/Met) serine and methionine; (IMP) inosine monophosphate.

their parents $(P=0.094)$ (Fig. 5A). The majority $(74.0 \%)$ of the heterotic F1 hybrids had ROS levels lower than the MPV of their parents, whereas the majority (77.8\%) of the depressed F1 hybrids had ROS levels higher than the MPV of their parents (Fig. 5B). tain the redox homeostasis, cells evolved a series of regulatory systems. The cofactors NADH and NADPH are key components in these systems (Rosenzweig et al. 2018). One of the major pathways contributing to NADH and NADPH production is $1 \mathrm{C}$ metabolism (Fan et al. 2014; Rosenzweig et al. 2018).

\section{C metabolism plays a key role in} thermotolerant heterosis in yeast

The nonadditive genes that were up-regulated in the heterotic F1 hybrids but down-regulated in the depressed F1 hybrids are mostly enriched in the GO terms 1C metabolism, IMP metabolism, and methionine and serine biosynthetic process (Fig. 3D,E). IMP metabolism requires 10-formyl-THF, which is produced by 1C metabolism (Ducker et al. 2016). Serine is an indispensable donator to the $1 \mathrm{C}$ unit that contributes to the folate cycle and the methionine cycle (Locasale 2013; Rosenzweig et al. 2018). Therefore, these processes are centered by $1 \mathrm{C}$ metabolism as shown in the GO enrichment network analysis (Fig. 3E). 1C metabolism is a universal metabolic process supporting multiple physiological processes as well as redox defense (Locasale 2013; Fan et al. 2014; Ducker and Rabinowitz 2017; Rosenzweig et al. 2018). To main-
A

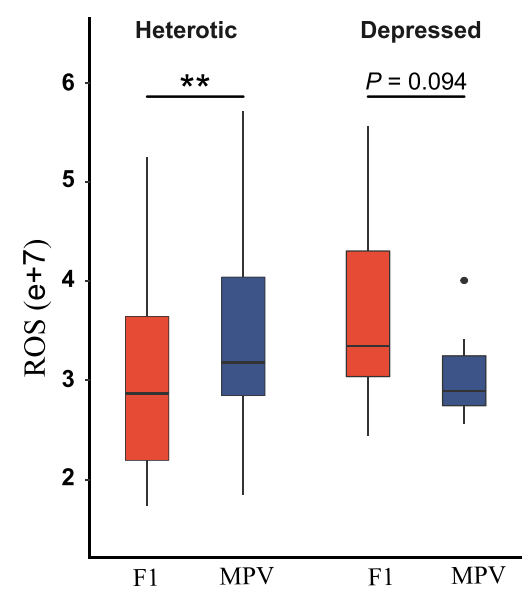

B

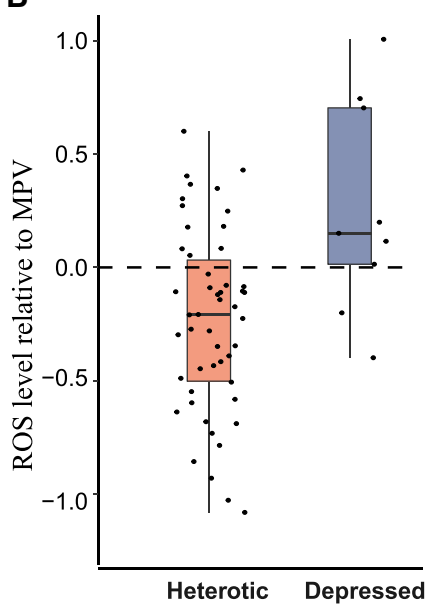

Figure 5. Levels of reactive oxygen species (ROS) within cells of F1 hybrids of wild S. cerevisiae and their parents growing at $40^{\circ} \mathrm{C}$. (A) Cellular ROS levels of $\mathrm{F} 1$ hybrids and average cellular ROS levels of their parents (MPV) in the groups of heterotic and depressed F1 hybrids, respectively. $\left(^{* *}\right) P<0.01$ (MannWhitney $U$ test). (B) Cellular ROS levels of heterotic and depressed F1 hybrids relative to the MPV. The relative ROS level in a F1 hybrid was calculated according to the formula $\log _{2}$ (F1/MPV). 
In S. cerevisiae, $A D E 3$ (C1-tetrahydrofolate synthase gene) is a key gene in the cytosolic $1 \mathrm{C}$ metabolism, which contributes to NADPH production in the pathway. MTD1 (NAD-dependent 5,10-methylenetetrahydrafolate dehydrogenase) contributes to the production of NADH in this pathway (Piper et al. 2000). These two genes were up-regulated in most heterotic but downregulated in most depressed F1 hybrids (Supplemental Fig. S6). We randomly selected four heterotic F1 hybrids and knocked out $A D E 3$ or MTD1 from them. The null mutants (ade $3 \Delta / \Delta$ or $m t d 1 \Delta /$ $\Delta$ ) of the hybrids showed a remarkable decrease in growth performance at $40^{\circ} \mathrm{C}$ (Fig. 6A,B; Supplemental Fig. S7A,B). The addition of $\mathrm{N}$-acetyl-L-cysteine, which is a well-characterized antioxidant able to scavenge ROS (Zafarullah et al. 2003), rescued or improved the growth of the ade $3 \Delta / \Delta$ and $m t d 1 \Delta / \Delta$ mutants at $40^{\circ} \mathrm{C}$ but did not influence or even compromise the growth of the wild-type strains (Fig. 6A,B; Supplemental Fig. S7A,B). Both or at least one of the mutants showed significantly increased cellular ROS levels and $\mathrm{NADP}^{+} / \mathrm{NADPH}$ ratios compared with the wild-type strains at $40^{\circ} \mathrm{C}$ (Fig. 6C; Supplemental Fig. S7C). These results suggest that the up-regulation of the cytosolic 1C metabolism pathway contributes to the heterosis of F1 hybrids of yeast at high temperature by providing more power for redox defense.

To test if the up-regulation of $A D E 3$ could improve the fitness of depressed hybrids, we expressed multiple copies of the gene in three depressed hybrids and their parents using an expression plasmid. However, we did not observe growth improvement of the mutants at $40^{\circ} \mathrm{C}$ (Supplemental Fig. S8). On the other hand, we found that the growth of the depressed hybrids and their parents at $40^{\circ} \mathrm{C}$ was significantly improved by the addition of $\mathrm{N}$-acetyl-L-cysteine (Supplemental Fig. S8). The data suggest that elevated oxidative stress contributes to the decreased fitness of depressed F1 hybrids at high temperature. However, artificially up-regulating only one gene associated with $1 \mathrm{C}$ metabolism is unable to improve the outcome of the whole pathway. It is also possible that other pathways are required for the improvement of redox homeostasis or for the manifestation of thermotolerant heterosis in yeast.

\section{Discussion}

We show here that heterosis is prevalent in F1 hybrids of wild $S$. cerevisiae strains at high temperature. The degree of heterosis and parental genetic distance show a hump-shaped relationship. Improved redox homeostasis and energy-use efficiency caused by the up-regulation (HP-like or over HP level) of a limited number of genes associated with metabolism pathways centered by 1C metabolism probably play a key role in heterosis of yeast at high temperature. We provide new insights into molecular mechanisms underlying heterosis and thermotolerance of yeast and new clues for a better understanding of the molecular basis of heterosis in plants and animals.

The result of our study does not agree with that of Plech et al. (2014), who did not detect heterosis in hybrids formed by wild $S$. cerevisiae strains. The following factors are probably responsible for the inconsistency. First, the growth performance was generally tested at $30^{\circ} \mathrm{C}$ in the previous study. In our study, when average fitness of the parental strains and $\mathrm{F} 1$ hybrids was compared at $30^{\circ} \mathrm{C}$, the latter also did not show heterosis (Supplemental Fig. S1). However, evident heterosis was detected in the F1 hybrids growing at $40^{\circ} \mathrm{C}$ (Fig. 1). Second, the strains used by Plech et al. (2014) were not genetically intact. Both homozygous and heterozygous diploid strains contained one or two of the hphMX4, kanMX4, and natMX 4 cassettes. Another study has shown that the genetic markers have a significant cost on the growth of Saccharomyces strains, and unmarked strains usually grow better than the marked
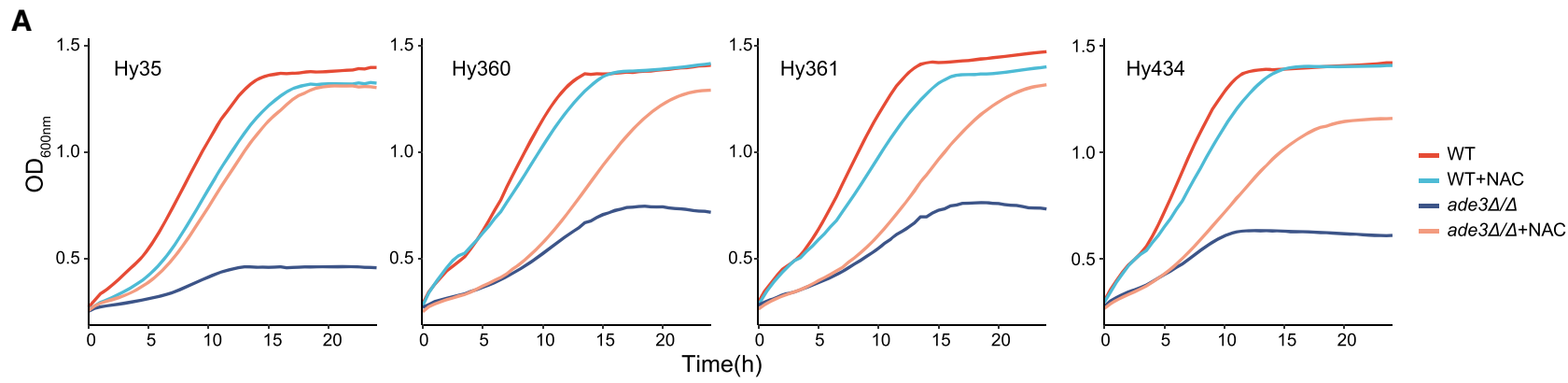

B

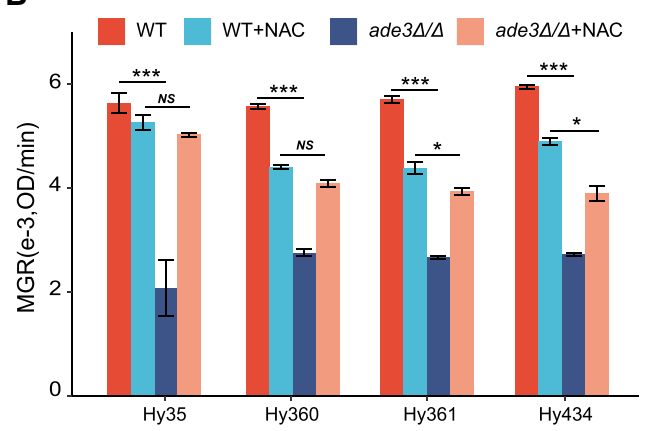

C

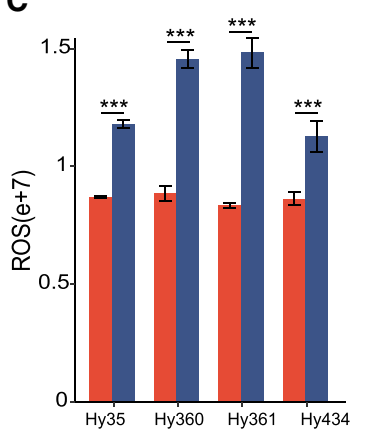

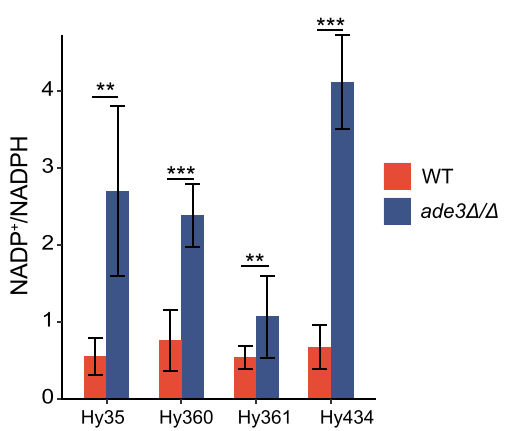

Figure 6. Effects of $A D E 3$ gene deletion on the growth and cellular oxidative stress of $\mathrm{F} 1$ hybrids of wild $\mathrm{S}$. cerevisiae at $40^{\circ} \mathrm{C}$. ( $A$ ) Growth curves of wild types (WTs) and ade $3 \Delta / \Delta$ mutants of four F1 hybrids without or with $15 \mathrm{mM} \mathrm{N}$-acetyl-L-cysteine (NAC) in the medium. (B) MGRs of wild types and ade $3 \Delta / \Delta$ mutants of four $\mathrm{F} 1$ hybrids without or with $15 \mathrm{mM} \mathrm{NAC}$ in the medium. (C) Comparisons of cellular ROS levels (left) and NADP ${ }^{+} / \mathrm{NADPH}$ ratios (right) between the wild types and ade $3 \Delta / \Delta$ mutants of four F1 hybrids. $\left(^{*}\right) P<0.05 ;\left({ }^{* *}\right) P<0.01 ;\left({ }^{* * *}\right) P<0.001 ;($ NS) not significant, $P>0.05$ (Mann-Whitney $U$ test). Error bars, SDs ( $\mathrm{n} \geq 3)$.

\section{Genome Research}

www.genome.org 
versions of the same strains (Bernardes et al. 2017). In our study, we used original homozygous wild strains, and the hybrids were generated by spore-to-spore mating without any genetic markers. Although the F1 hybrids did not show evident heterosis in optimum growth conditions at $30^{\circ} \mathrm{C}$, they most likely will have an adaptive advantage in food and ethanol fermentation environments, in which yeast cells encounter various stresses, including high osmolarity, elevated temperature, and increased ethanol concentration. All these stresses can cause an elevated ROS level in the cells (Auesukaree 2017). This might explain the prevalence of heterozygosity in domesticated strains of $S$. cerevisiae (Duan et al. 2018).

A correlation between heterosis and genetic distance between inbreeding parental lines was generally observed in plants (East 1936; Chen 2010; Pandey et al. 2018) but was not observed in previous studies on Saccharomyces yeasts (Shapira et al. 2014; Bernardes et al. 2017). Shapira et al. (2014) did not observe a correlation between heterosis in hybrids and parental genetic distances in S. cerevisiae. Although Bernardes et al. (2017) showed a significant increase in MPH with increasing genetic distance, the relationship was driven entirely by the interspecific (S. cerevisiae $\times S$. paradoxus) hybrids. Our result implies that the degree of thermotolerant heterosis in yeast increases along with the increase of parental genetic distance but decrease when the distance exceeds an optimal mating distance. The result is consistent with the theory prediction that the fitness of an individual hybrid is maximized when the genetic distance between its parents (i.e., mating distance) is neither too small nor too large (Wei and Zhang 2018). The nucleotide diversity and the maximal intraspecific genetic distance of $S$. cerevisiae are $6.63 \times 10^{-3}$ and $16.39 \times 10^{-3}$, respectively (Duan et al. 2018). The estimated optimal mating distances (7.42 $\times 10^{-3}$ to $10.56 \times 10^{-3}$ ), as shown in Supplemental Table S2, also agree with the prediction of Wei and Zhang (2018) that the optimal mating distances are generally slightly greater than the nucleotide diversities of the species concerned but smaller than the observed maximal intraspecific genetic distances.

The conclusion of our study is apparently not in accordance with the regulatory incompatibility model, which attributes heterosis to the impairment of growth-limiting pathways in the hybrid (Bar-Zvi et al. 2017; Herbst et al. 2017). This hypothesis was proposed based on the study of one interspecific hybrid created by mating haploid strains of $S$. cerevisiae and $S$. paradoxus, with their $\mathrm{HO}$ genes being replaced by different drug-resistant genetic markers (Herbst et al. 2017). Because only one hybrid was used in the study of Herbst et al. (2017), it is not sure if the phenomenon observed is common in yeast hybrids. The increased DNA damages observed in the hybrid suggest that such hybrids will not have an adaptive advantage when living in nature. Indeed, although interspecific hybrids of different Saccharomyces species commonly occur in fermentation environments (Hittinger 2013; Gallone et al. 2019; Langdon et al. 2019), interspecific hybrids of S. cerevisiae and $S$. paradoxus have rarely been found (Pontes et al. 2019). Nevertheless, Herbst et al. (2017) showed the importance of gene regulation in heterosis of yeast hybrids.

On the other hand, the result of our study is in agreement with the energy-use efficiency hypothesis (Ginn 2010, 2017; Goff 2011). This hypothesis was proposed mainly based on the observation that inbred organisms usually have increased rates of protein turnover relative to noninbred organisms (Hawkins et al. 1986; Hedgecock et al. 1996; Bayne 2004). According to this model, inbred organisms consume more energy in the degradation of misfolded and aggregated proteins by the protein quality control systems (Ginn 2010), whereas hybrids achieve greater energy efficiency via selective expression of parental alleles encoding more stable proteins (Goff 2011), or reduce the rate of toxic soluble oligomer formation (Ginn 2017). A weakness of this hypothesis is that it was proposed only on the basis of theoretical analyses. Here we provide substantial evidence at the transcriptome level and an alternative more reasonable explanation to the model. The downregulation of genes associated with protein quality control systems in the heterotic F1 hybrids of S. cerevisiae (Figs. 3, 4; Supplemental Fig. S5) suggests a lower protein turnover rate in the hybrids than in the parental strains and depressed hybrids. The result of our RNA-seq analysis suggests that the heterotic F1 hybrids achieve lower protein turnover rate through the up-regulation of genes in the 1C metabolism and related pathways (Figs. 3, 4; Supplemental Fig. S6), leading to improved redox homeostasis in the hybrids (Fig. 5). The reduced level of oxidative stress results in reduced errors in protein synthesis and folding and subsequently to reduced expression levels of genes associated with protein quality control systems, including protein folding, chaperons, proteolysis, and autophagy (Figs. 3, 4; Supplemental Fig. S5). In addition, the improved redox homeostasis also leads to the reduced expression levels of genes associated with DNA repair, stress responses, and ion homeostasis, as well as many other genes (Figs. 3, 4; Supplemental Fig. S5). Therefore, the heterotic F1 hybrids achieve improved energy-use efficiency by the down-regulation of more genes at the cost of the up-regulation of only a limited number of genes associated with key pathways for stress defense.

Gene expression profiling has been extensively used to illuminate molecular mechanisms of heterosis in plant hybrids, and some studies have shown that specific genes or pathways might contribute to heterosis for a number of traits in maize, rice, the tomato, and Arabidopsis (Hoecker et al. 2008; Wei et al. 2009; Krieger et al. 2010; Gonzalez-Bayon et al. 2019). However, the working models of these genes are still unclear, and whether such genes contribute to general molecular mechanisms of heterosis remains to be determined. From the genes and pathways with expression levels significantly correlated with heterosis of the F1 hybrids of $S$. cerevisiae, we infer that the up-regulation (overdominance or HP dominance) of genes associated with $1 \mathrm{C}$ metabolism and related pathways might be causative for the manifestation of heterosis of the yeast. As mentioned above, 1C metabolism as a universal metabolic process provides cells with the building blocks, as well as the reducing power, necessary to maintain high rates of proliferation (Rosenzweig et al. 2018). The up-regulation of these genes endows yeast cells with an improved ability to scavenge ROS triggered by high temperature or other stresses, contributing to the manifestation of growth heterosis of the hybrids. Because the growth rate is proportional to the total translation rate and to the number of ribosomes per cell (Lin and Amir 2018), the higher expression level of genes responsible for ribosome biogenesis and other pathways associated with translation observed in the heterotic F1 hybrids (Fig. 3) is probably the effect, not the cause, of heterosis. The observed association between decreased rates of protein metabolism and heterosis in animals and plants (Hawkins et al. 1986; Hedgecock et al. 1996; Bayne 2004) implies a possible role of $1 \mathrm{C}$ metabolism process in the manifestation of heterosis of these species, for reduced ROS level in the cell contributed by $1 \mathrm{C}$ metabolism will decrease protein damages, thus leading to decreased protein turnover rate.

Why genes in 1C metabolism and related processes are upregulated in the F1 hybrids remains to be illuminated. Previous studies have shown that additive expression of a gene is 
attributable mostly to cis-regulation, whereas nonadditive expression is attributable mostly to trans-regulation (Lemos 2008; Wei et al. 2009; McManus et al. 2010). Genes with antagonistic cis-trans interactions are more likely to be overdominant or underdominant in hybrids (Hochholdinger and Hoecker 2007; Lemos 2008; McManus et al. 2010; Schaefke et al. 2013). The expression patterns of genes in the $1 \mathrm{C}$ metabolism and related processes in the F1 hybrids suggest that they are most likely subjected to trans-regulation or antagonistic cis-trans regulation. Trans-acting regulators (e.g., transcription factors and chromatin modifiers) are diffusible, and thus, the genes of the F1 hybrids are subjected to the regulation of these regulators from both parents. The trans-acting regulators with slightly deleterious mutations in one parent can probably be complemented by those from the other parent in the hybrid cells, resulting in HP dominance if the genes are subjected to only trans-regulation or in over- or underdominance if the genes are subjected to cis-trans regulation (Hochholdinger and Hoecker 2007; Lemos 2008; McManus et al. 2010; Schaefke et al. 2013). These mechanisms are in accordance with the dominance model (complementation of slightly deleterious recessive alleles of trans-acting regulator genes) and with the epistasis model (interactions between cis- and trans-acting elements), respectively. The largely positive correlation between heterosis and parental genetic distance until an optimal mating distance observed in this study implies that the complementation model may play a role. However, the benefit of the complementation will probably be offset by the harm of genetic incompatibility when the parental genetic distance is beyond the optimal mating distance, as shown in this study (Fig. 1; Wei and Zhang 2018).

To our knowledge, we are probably the first to use outbreeding depressed F1 hybrids as contrast in the study on the molecular mechanisms of heterosis. Although the number of depressed F1 hybrids generated and used in this study is limited, they are helpful to figure out the genes responsible for heterosis and manifest the contribution of these genes. As for the heterosis, genes associated with $1 \mathrm{C}$ metabolism and the related processes are apparently also responsible for the manifestation of the depression. The down-regulation of these genes might compromise redox homeostasis, leading to increased level of ROS (Fig. 5), which in turn causes more DNA and protein damages. We therefore observed elevated expression levels of genes associated with DNA repair and protein quality control systems in the depressed hybrids (Figs. 3, 4; Supplemental Fig. S5). The increased level of oxidative stress might also compromise homeostasis of many other metabolism processes, thus triggering the up-regulation of genes responsible for cellular homeostasis and stress responses (Figs. 3, 4; Supplemental Fig. S5). Therefore, the depressed F1 hybrids showed an opposite gene expression pattern to the heterotic F1 hybrids and reduced growth rate and efficiency at high temperature. The down-regulation (LP-like or below LP level) of genes in 1C metabolism and the related processes is probably caused by regulatory incompatibility or antagonistic cis-trans interactions. As discussed above, antagonistic cis-trans interactions are more likely to be not only overdominant (above HP) but also underdominant (below LP) in hybrids (Hochholdinger and Hoecker 2007; Lemos 2008; McManus et al. 2010; Schaefke et al. 2013).

Aneuploidy is probably another cause of outbreeding depression in S. cerevisiae. The majority $(7 / 9,77.8 \%)$ of the depressed F1 hybrids used in our RNA-seq analysis share a common parental strain BJ22 (Supplemental Table S2). We found that only $22.7 \%$ (4/15) of the F1 hybrids generated by crossing BJ22 with other strains showed $\mathrm{MPH}$, much lower than the overall proportion
(96.2\%) of the F1 hybrids showing MPH (Fig. 1; Supplemental Table S1). The result implies the responsibility of this specific strain for the depression. Our previous study has shown that strain BJ22 is aneuploid $(2 \mathrm{~N}+5)$, which has two extra copies of Chromosome I, two extra copies of Chromosome III, and one extra copy of Chromosome VI (Duan et al. 2018). The hybrids with BJ22 as one parent are most likely also aneuploid. Chromosomal differences may generate outbreeding depression (Frankham et al. 2011). Investigations in S. cerevisiae have revealed growth defects of aneuploid cells resulting from cell cycle delays, DNA and protein damage, protein folding errors, and elevated ROS levels (Torres et al. 2007; Tsai and Nelliat 2019). The result of RNA-seq analysis of the depressed F1 hybrids obtained in our study is consistent with the phenomena observed in the previous studies. Illumination of the mechanisms causing outbreeding depression is certainly helpful for a better understanding of the mechanisms underlying heterosis.

Finally, it is worth noting that the physiological and molecular interpretations of the mechanisms underlying heterosis presented in this study are only valid for $S$. cerevisiae hybrids growing at high temperature. Whether the yeast hybrids show similar degrees of heterosis and gene expression variations under other stressful conditions remains to be tested.

\section{Methods}

\section{Parental yeast strains and generation of F1 hybrids}

A total of 53 parental strains (Supplemental Table S1) were selected from different wild lineages of $S$. cerevisiae, which were shown to be homozygous by genome analysis (Duan et al. 2018). Parental genetic distance as indicated by the percentage of SNP difference between two parental strains were determined using the Python software package EggLib (De Mita and Siol 2012).

The parental strains were inoculated onto YPD agar (w/v, 1\% yeast extract, $2 \%$ peptone, $2 \% \mathrm{D}$-glucose, and $2 \%$ agar) plates for $24 \mathrm{~h}$ at $30^{\circ} \mathrm{C}$ and then transferred onto sporulation plates $(1 \%$ potassium acetate and $2 \%$ agar) and incubated for $3-4 \mathrm{~d}$ at $30^{\circ} \mathrm{C}$. Asci were collected and digested in $10 \mathrm{mg} / \mathrm{mL}$ Zymolyase (20T) solution for $15 \mathrm{~min}$ at $30^{\circ} \mathrm{C}$. Tetrad dissection and spore-to-spore mating were performed under an MSM 400 micromanipulator microscope (Singer Instruments) on YPD plates. The colonies formed by zygotes that were judged by the mating structure of paired spores were selected. Finally, a total of 641 F1 hybrids were created.

\section{Growth performance test}

The mitotic proliferative abilities of parental strains and F1 hybrids in YPD broth at $30^{\circ} \mathrm{C}$ and $40^{\circ} \mathrm{C}$, respectively, were tested in duplicates in microplates using a Bioscreen analyser $\mathrm{C}$ (Thermic Labsystems) as described by Warringer and Blomberg (2003). For testing the effect of $\mathrm{N}$-acetyl-L-cysteine on the growth of yeast strains, the compound was added to YPD broth to a final concentration of $15 \mathrm{mM}$ (Topf et al. 2018). The fitness variables, including maximum growth rate and growth efficiency, were extracted from high-density growth curves as described previously (Duan et al. 2019).

\section{Correlation analyses between heterosis and parental genetic distance}

The relationship between heterosis and parental genetic distance was analyzed using linear and nonlinear models as described by Wei and Zhang (2018) with minor modifications. Specifically, growth performance was determined at $40^{\circ} \mathrm{C}$ as described above.

\section{Genome Research}

www.genome.org 
We binned the hybrids with similar parental genetic distance $(G)$ under a window size of $1 \times 10^{-3}$, computed the average $G$ for each bin, and then calculated the average performance of the hybrids for each window. The quadratic equations were fitted by the nonlinear least-squares method using the $l m$ function in R following the formula performance $\sim \mathrm{G} / 2+\mathrm{G}$, and the linear model was computed following the formula performance $\sim \mathrm{G}$.

\section{RNA-seq, gene expression profiling, and GO enrichment analyses}

The F1 hybrids (59 strains) and their parents (35 strains) selected for RNA-seq analysis are listed in Supplemental Table S2. Yeast cells were incubated in YPD broth at $40^{\circ} \mathrm{C}$ and harvested at the logphase. Total RNA was extracted and processed using a commercial RNA purification kit (Thermo Fisher Scientific) according to the manufacturer's protocols. RNA samples were sequenced on an Illumina HiSeq X Ten platform, and at least two Gb clear reads were obtained for each strain.

The FASTX toolkit (https://github.com/agordon/fastx toolkit/) was used to evaluate the raw data and discard low-quality reads. The clean reads were aligned to the reference genome of strain S288C using HISAT2 (Pertea et al. 2016), and the numbers of reads mapped to each gene were counted by HTSeq (Anders et al. 2015). The Q30 was $>89 \%$, and $>85 \%$ of the reads were mapped to the reference genome (Supplemental Table S3). The gene expression levels were calculated based on the values of fragments per kilobases per million mapped reads (FPKM). The genes with an expression level $>1$ FPKM were identified as actively expressed genes and subjected for further analyses. The genes with expression levels in a F1 hybrid that significantly deviated from the average expression levels of the genes in its parents (MPV) determined using the algorithm DESeq $(P \leq 0.01, \quad$ FDR $\leq 0.1)$ (Groszmann et al. 2015) were identified as nonadditive genes. GO enrichment analysis of nonadditive genes was implemented using Metascape (Zhou et al. 2019), and the GO terms with corrected $P<0.01$ were considered as significantly enriched. Enrichment networks were then constructed based on functional similarities of the terms that were measured using an algorithm adopts kappa statistics (Huang et al. 2009). The algorithm quantitatively measures the degree of the agreement of how genes share the similar annotation terms, resulting in kappa similarities ranging from zero to one. Enrichment networks were created by representing each enriched term as a node and connecting pairs of nodes with kappa similarities above 0.3 (Zhou et al. 2019).

\section{Gene expression pattern analysis of nonadditive genes}

Based on the expression level of a gene in a F1 hybrid relative to the expression level of the gene in the HP and LP, a nonadditive gene was classified further into one of the five patterns: namely, additive $(\mathrm{HP}>\mathrm{F} 1>\mathrm{LP})$, HP-like $(\mathrm{F} 1=\mathrm{HP})$, LP-like $(\mathrm{F} 1=\mathrm{LP})$, above HP (F1 > HP) and below LP (F1 <LP) as defined previously (Stupar et al. 2008; Rapp et al. 2009; Tian et al. 2018). For each nonadditive gene, its FPKM counts in a F1 hybrid, and in its parents were logtransformed and tested for significant deviations between the F1 hybrid and its parents and between the two parents using oneway analysis of variance (ANOVA). Subsequently, we assessed pairwise contrasts using the TukeyHSD post hoc test $(P<0.05)$.

\section{Validation of RNA-seq data by qRT-PCR}

qRT-PCR was used to validate the gene expression levels determined by RNA-seq analysis. Nineteen RNA samples were randomly selected from the samples subjected to RNA-seq analysis, and cDNA libraries were constructed using the first-strand cDNA synthesis with the PrimeScript RT reagent kit with gDNA Eraser
(TaKaRa). Seventeen genes were selected, and primers were designed using the Primer Express 3.0 software (Applied Biosystems) (Supplemental Table S4). The qRT-PCR was performed using a Roche LightCycler480 II real-time PCR system (Roche). Each reaction contained $10 \mu \mathrm{L}$ of $2 \times$ FastStart universal SYBR Green master (Roche), $2.0 \mu \mathrm{L}$ diluted cDNA, and $0.8 \mu \mathrm{L}$ each of the forward and reverse primers in a final volume of $20 \mu \mathrm{L}$. The PCR conditions consisted of predenaturation for $5 \mathrm{~min}$ at $95^{\circ} \mathrm{C}$, followed by 40 cycles of $15 \mathrm{sec}$ at $95^{\circ} \mathrm{C}, 25 \mathrm{sec}$ at $60^{\circ} \mathrm{C}$, and $25 \mathrm{sec}$ at $72^{\circ} \mathrm{C}$. At the end of the PCR cycles, a melting curve analysis was performed to validate the specificity of the PCR product. The housekeeping gene LYS14 was used as a reference for normalization, and three replicates were performed for each cDNA sample. Data analysis was performed as reported previously (Livak and Schmittgen 2001).

\section{ROS and $\mathrm{NADP}^{+} / \mathrm{NADPH}$ ratio measurement}

ROS levels in yeast cells were assayed with 2,7'-dichlorodihydrofluorescein diacetate (Sigma-Aldrich H2DCF-DA). Briefly, strains were incubated in YPD broth for $4 \mathrm{~h}$ at $40^{\circ} \mathrm{C}$, and then H2DCFDA was added to a final concentration of $10 \mu \mathrm{M}$ and incubated for $30 \mathrm{~min}$ in the dark at $40^{\circ} \mathrm{C}$. Yeast cells were collected by centrifuge and washed three times with phosphate buffered saline (PBS; $135 \mathrm{mM} \mathrm{NaCl}, 2.7 \mathrm{mM} \mathrm{KCl}, 1.5 \mathrm{mM} \mathrm{KH}_{2} \mathrm{PO}_{4}$, and $8 \mathrm{mM} \mathrm{K}_{2} \mathrm{HPO}_{4}$ at $\mathrm{pH}$ 7.2). Fluorescence intensity was measured by spectrophotometry with excitation of $488 \mathrm{~nm}$ and emission of $525 \mathrm{~nm}$.

$\mathrm{NADP}^{+}$and NADPH were extracted and measured using the $\mathrm{NADP}^{+} / \mathrm{NADPH}$ quantitation kit (Sigma-Aldrich) as described by Zhang et al. (2016).

\section{Knocking out $A D E 3$ and MTD1 genes}

Gene deletion was performed using the protocol as described in our previous study (Duan et al. 2019). Shortly, for deleting the first copy of the target gene, the plasmid pKAN-ADE3 or pKAN-MTD1 was generated by inserting two DNA fragments containing sequences homologous to the $5^{\prime}$ - and $3^{\prime}$-terminals of $A D E 3$ or MTD1 of strain BJ23 into the plasmid pKAN. The plasmids pAG32-ADE3 and pAG32-MTD1 were constructed in the same way for deleting the second copy of the genes. We finally constructed mutant strains with ade3::hphMX/ade3::kanMX or $m t d 1:: h p h M X / m t d 1:: k a n M X$. The concentration of G418 and hygromycin used in the YPD plates for mutant selection is 300 $\mu \mathrm{g} / \mathrm{mL}$ and $400 \mu \mathrm{g} / \mathrm{mL}$, respectively.

\section{Overexpression of $A D E 3$}

To overexpress the gene $A D E 3$, an expression vector was constructed and transformed into target strains using the protocol as described by Duan et al. (2019) with minor modifications. In brief, the hphMX marker was amplified from the plasmid pAG32, and the DNA segment including the promoter, open reading frame, and terminator of $A D E 3$ was amplified from the wild S. cerevisiae strain BJ23. The marker and the DNA segment were fused into the expression plasmid pRS423, which was then transformed into targeted strains.

\section{Statistical analysis}

Standard statistical analyses were performed in R project (v3.3.1) (R Core Team 2016). The statistical significance was obtained using the Student's $t$-test or Mann-Whitney $U$ test executed by the t.test or wilcox.test function of $\mathrm{R}$ project with a two-sided alternative hypothesis. ANOVA was used in gene-expression-level variation analysis. 


\section{Data access}

The raw RNA-sequencing data generated in this study have been submitted to the NCBI BioProject database (https:// www.ncbi.nlm.nih.gov/bioproject/) under accession number PRJNA659808. The information of the RNA-sequencing data obtained from every sample is available in Supplemental Table S4.

\section{Competing interest statement}

The authors declare no competing interests.

\section{Acknowledgments}

This study was supported by the Chinese Academy of Sciences (grants no. QYZDJ-SSW-SMC013 and no. 153211KYSB20160029) and the Ministry of Science and Technology of China (KY20 1701011, the Science and Technology Partnership Program).

\section{References}

Altman BJ, Stine ZE, Dang CV. 2016. From Krebs to clinic: glutamine metabolism to cancer therapy. Nat Rev Cancer 16: 619-634. doi: $10.1038 / \mathrm{nrc}$ .2016 .71

Anders S, Pyl PT, Huber W. 2015. HTSeq-a Python framework to work with high-throughput sequencing data. Bioinformatics 31: 166-169. doi:10 .1093/bioinformatics/btu638

Auesukaree C. 2017. Molecular mechanisms of the yeast adaptive response and tolerance to stresses encountered during ethanol fermentation. Biosci Bioeng 124: 133-142. doi:10.1016/j.jbiosc.2017.03.009

Baldauf JA, Marcon C, Lithio A, Vedder L, Altrogge L, Piepho HP, Schoof H, Nettleton D, Hochholdinger F. 2018. Single-parent expression is a general mechanism driving extensive complementation of non-syntenic genes in maize hybrids. Curr Biol 28: 431-437.e4. doi:10.1016/j.cub .2017.12.027

Bar-Zvi D, Lupo O, Levy AA, Barkai N. 2017. Hybrid vigor: the best of both parents, or a genomic clash? Curr Opin Syst Biol 6: 22-27. doi:10.1016/j .coisb.2017.08.004

Bayne BL. 2004. Phenotypic flexibility and physiological tradeoffs in the feeding and growth of marine bivalve molluscs. Integr Comp Biol 44: 425-432. doi:10.1093/icb/44.6.425

Bernardes JP, Stelkens RB, Greig D. 2017. Heterosis in hybrids within and between yeast species. J Evol Biol 30: 538-548. doi:10.1111/jeb.13023

Birchler JA, Yao H, Chudalayandi S, Vaiman D, Veitia RA. 2010. Heterosis. Plant Cell 22: 2105-2112. doi:10.1105/tpc. 110.076133

Blein-Nicolas M, Albertin W, Da Silva T, Valot B, Balliau T, MasneufPomarède I, Bely M, Marullo P, Sicard D, Dillmann C, et al. 2015. A systems approach to elucidate heterosis of protein abundances in yeast. Mol Cell Proteomics 14: 2056-2071. doi:10.1074/mcp.M115.048058

Bruce AB. 1910. The mendelian theory of heredity and the augmentation of vigor. Science 32: 627-628. doi:10.1126/science.32.827.627-a

Charlesworth D, Willis JH. 2009. The genetics of inbreeding depression. Nature Rev Genet 10: 783-796. doi:10.1038/nrg2664

Chen ZJ. 2010. Molecular mechanisms of polyploidy and hybrid vigor. Trends Plant Sci 15: 57-71. doi:10.1016/j.tplants.2009.12.003

Chen ZJ. 2013. Genomic and epigenetic insights into the molecular bases of heterosis. Nature Rev Genet 14: 471-482. doi:10.1038/nrg3503

Darwin C. 1876. The effects of cross and self-fertilisation in the vegetable kingdom. John Murray, London.

Davenport CB. 1908. Degeneration, albinism and inbreeding. Science 28: 454-455. doi:10.1126/science.28.718.454-b

De Mita S, Siol M. 2012. EggLib: processing, analysis and simulation tools for population genetics and genomics. BMC Genet 13: 27. doi:10 .1186/1471-2156-13-27

Duan SF, Han PJ, Wang QM, Liu WQ, Shi JY, Li K, Zhang XL, Bai FY. 2018. The origin and adaptive evolution of domesticated populations of yeast from Far East Asia. Nat Commun 9: 2690. doi:10.1038/s41467-01805106-7

Duan SF, Shi JY, Yin Q, Zhang RP, Han PJ, Wang QM, Bai FY. 2019. Reverse evolution of a classic gene network in yeast offers a competitive advantage. Curr Biol 29: 1126-1136.e5. doi:10.1016/j.cub.2019.02.038

Ducker GS, Rabinowitz JD. 2017. One-carbon metabolism in health and disease. Cell Metab 25: 27-42. doi:10.1016/j.cmet.2016.08.009

Ducker GS, Chen L, Morscher RJ, Ghergurovich JM, Esposito M, Teng X, Kang YB, Rabinowitz JD. 2016. Reversal of cytosolic one-carbon flux compensates for loss of the mitochondrial folate pathway. Cell Metab 23: 1140-1153. doi:10.1016/j.cmet.2016.04.016

East EM. 1936. Heterosis. Genetics 21: 375-397. doi:10.1007/BF02982541

Fan J, Ye JB, Kamphorst JJ, Shlomi T, Thompson CB, Rabinowitz JD. 2014 Quantitative flux analysis reveals folate-dependent NADPH production. Nature 510: 298-302. doi:10.1038/nature 13236

Fiévet JB, Dillmann C, de Vienne D. 2010. Systemic properties of metabolic networks lead to an epistasis-based model for heterosis. Theor Appl Genet 120: 463-473. doi:10.1007/s00122-009-1203-2

Fiévet JB, Nidelet T, Dillmann C, de Vienne D. 2018. Heterosis is a systemic property emerging from non-linear genotype-phenotype relationships: evidence from in vitro genetics and computer simulations. Front Genet 9: 26. doi:10.3389/fgene.2018.00159

Foyer CH, Noctor G. 2016. Stress-triggered redox signalling: what's in pROSpect? Plant Cell Environ 39: 951-964. doi:10.1111/pce.12621

Frankham R, Ballou JD, Eldridge MDB, Lacy RC, Ralls K, Dudash MR, Fenster CB. 2011. Predicting the probability of outbreeding depression. Conserv Biol 25: 465-475. doi:10.1111/j.1523-1739.2011.01662.X

Fujimoto R, Uezone K, Ishikura S, Osabe K, Peacoc WJ, Dennis ES. 2018. Recent research on the mechanism of heterosis is important for crop and vegetable breeding systems. Breed Sci 68: 145-158. doi:10.1270/ jsbbs. 17155

Gallone B, Steensels J, Mertens S, Dzialo MC, Gordon JL, Wauters R, Thesseling FA, Bellinazzo F, Saels V, Herrera-Malaver B, et al. 2019 Interspecific hybridization facilitates niche adaptation in beer yeast. Nat Ecol Evol 3: 1562-1575. doi:10.1038/s41559-019-0997-9

Ginn BR. 2010. The implications of gene heterozygosity for protein folding and protein turnover. J Theor Biol 265: 554-564. doi:10.1016/j.jtbi.2010 .05 .023

Ginn BR. 2017. The thermodynamics of protein aggregation reactions may underpin the enhanced metabolic efficiency associated with heterosis, some balancing selection, and the evolution of ploidy levels. Prog Biophys Mol Biol 126: 1-21. doi:10.1016/j.pbiomolbio.2017.01.005

Goff SA. 2011. A unifying theory for general multigenic heterosis: energy efficiency, protein metabolism, and implications for molecular breeding. New Phytol 189: 923-937. doi:10.1111/j.1469-8137.2010.03574.x

Gonzalez-Bayon R, Shen YF, Groszmann M, Zhu AY, Wang AH, Allu AD Dennis ES, Peacock WJ, Greaves IK. 2019. Senescence and defense pathways contribute to heterosis. Plant Physiol 180: 240-252. doi:10.1104/ pp.18.01205

Govindaraju DR. 2019. An elucidation of over a century old enigma in genetics: heterosis. PLOS Biol 17: e3000215. doi:10.1371/journal.pbio 3000215

Groszmann M, Gonzalez-Bayon R, Lyons RL, Greaves IK, Kazan K, Peacock WJ, Dennis ES. 2015. Hormone-regulated defense and stress response networks contribute to heterosis in Arabidopsis F1 hybrids. Proc Natl Acad Sci 112: E6397-E6406. doi:10.1073/pnas.1519926112

Guo M, Rupe MA, Dieter JA, Zou JJ, Spielbauer D, Duncan KE, Howard RJ, Hou ZL, Simmons CR. 2010. Cell Number Regulator1 affects plant and organ size in maize: implications for crop yield enhancement and heterosis. Plant Cell 22: 1057-1073. doi:10.1105/tpc.109.073676

Hawkins AJS, Bayne BL, Day AJ. 1986. Protein turnover, physiological energetics and heterozygosity in the blue mussel, Mytilus edulis: the basis of variable age-specific growth. Proc $R$ Soc Lond B 229: 161-176. doi:10 $.1098 /$ rspb.1986.0080

Hedgecock D, McGoldrick DJ, Manahan DT, Vavra J, Appelmans N, Bayne BL. 1996. Quantitative and molecular genetic analyses of heterosis in bivalve molluscs. J Exp Mar Biol Ecol 203: 49-59. doi:10.1016/0022-0981 (96)02569-5

Herbst RH, Bar-Zvi D, Reikhav S, Soifer I, Breker M, Jona G, Shimoni E, Schuldiner M, Levy AA, Barkai N. 2017. Heterosis as a consequence of regulatory incompatibility. BMC Biol 15: 15. doi:10.1186/s12915-0170373-7

Hittinger CT. 2013. Saccharomyces diversity and evolution: a budding model genus. Trends Genet 29: 309-317. doi:10.1016/j.tig.2013.01.002

Hochholdinger F, Baldauf JA. 2018. Heterosis in plants. Curr Biol 28: R1089R1092. doi:10.1016/j.cub.2018.06.041

Hochholdinger F, Hoecker N. 2007. Towards the molecular basis of heterosis. Trends Plant Sci 12: 427-432. doi:10.1016/j.tplants.2007.08.005

Hoecker N, Keller B, Muthreich N, Chollet D, Descombes P, Piepho HP, Hochholdinger F. 2008. Comparison of maize (Zea mays L.) $\mathrm{F}_{1}$-hybrid and parental inbred line primary root transcriptomes suggests organspecific patterns of nonadditive gene expression and conserved expression trends. Genetics 179: 1275-1283. doi:10.1534/genetics.108 .088278

Huang DW, Sherman BT, Lempicki RA. 2009. Systematic and integrative analysis of large gene lists using DAVID bioinformatics resources. Nat Protoc 4: 44-57. doi:10.1038/nprot.2008.211

Jansen T, Hoff JW, Jolly N, van Zyl WH. 2018. Mating of natural Saccharomyces cerevisiae strains for improved glucose fermentation and

\section{Genome Research}

www.genome.org 
lignocellulosic inhibitor tolerance. Folia Microbiol (Praha) 63: 155-168. doi:10.1007/s12223-017-0546-3

Jones DF. 1917. Dominance of linked factors as a means of accounting for heterosis. Genetics 2: 466-479. doi:10.1093/genetics/2.5.466

Krieger U, Lippman ZB, Zamir D. 2010. The flowering gene SINGLE FLOWER TRUSS drives heterosis for yield in tomato. Nature Genet 42: 459-463. doi:10.1038/ng.550

Langdon QK, Peris D, Baker EP, Opulente DA, Nguyen HV, Bond U, Gonçalves P, Sampaio JP, Libkind D, Hittinger CT. 2019. Fermentation innovation through complex hybridization of wild and domesticated yeasts. Nat Ecol Evol 3: 1576-1586. doi:10.1038/s41559019-0998-8

Langfelder P, Horvath S. 2008. WGCNA: an R package for weighted correlation network analysis. BMC Bioinformatics 9: 559. doi:10.1186/14712105-9-559

Lemos B. 2008. Gene expression: an X chromosome look beyond additive and nonadditive effects. Heredity (Edinb) 100: 543-544. doi:10.1038/ hdy. 2008.15

Li L, Lu K, Chen Z, Mu T, Hu Z, Li X. 2008. Dominance, overdominance and epistasis condition the heterosis in two heterotic rice hybrids. Genetics 180: $1725-1742$. doi:10.1534/genetics.108.091942

Li B, Zhang DF, Jia GQ, Dai JR, Wang SC. 2009. Genome-wide comparisons of gene expression for yield heterosis in maize. Plant Mol Biol Rep 27: 162-176. doi:10.1007/s11105-008-0068-x

Lin J, Amir A. 2018. Homeostasis of protein and mRNA concentrations in growing cells. Nat Commun 9: 4496. doi:10.1038/s41467-018-06714-z

Lippman ZB, Zamir D. 2007. Heterosis: revisiting the magic. Trends Genet 23: 60-66. doi:10.1016/j.tig.2006.12.006

Lippman ZB, Cohen O, Alvarez JP, Abu-Abied M, Pekker I, Paran I, Eshed Y, Zamir D. 2008. The making of a compound inflorescence in tomato and related nightshades. PLoS Biol 6: e288. doi:10.1371/journal.pbio .0060288

Livak KJ, Schmittgen TD. 2001. Analysis of relative gene expression data using real-time quantitative PCR and the $2^{-\Delta \Delta C T}$ method. Methods 25: 402-408. doi:10.1006/meth.2001.1262

Locasale JW. 2013. Serine, glycine and one-carbon units: cancer metabolism in full circle. Nat Rev Cancer 13: 572-583. doi:10.1038/nrc3557

Martí-Raga M, Peltier E, Mas A, Beltran G, Marullo P. 2017. Genetic causes of phenotypic adaptation to the second fermentation of sparkling wines in Saccharomyces cerevisiae. G3 (Bethesda) 7: 399-412. doi:10.1534/g3.116 .037283

Marullo P, Bely M, Masneuf-Pomarède I, Pons M, Aigle M, Dubourdieu D. 2006. Breeding strategies for combining fermentative qualities and reducing off-flavor production in a wine yeast model. FEMS Yeast Res 6: 268-279. doi:10.1111/j.1567-1364.2006.00034.x

McManus CJ, Coolon JD, Duff MO, Eipper-Mains J, Graveley BR, Wittkopp PJ. 2010. Regulatory divergence in Drosophila revealed by mRNA-seq. Genome Res 20: 816-825. doi:10.1101/gr.102491.109

Morano KA, Grant CM, Moye-Rowley WS. 2012. The response to heat shock and oxidative stress in Saccharomyces cerevisiae. Genetics 190: 11571195. doi:10.1534/genetics.111.128033

Naumov GI, Naumova ES, Kondratieva VI. 2006. The use of hybridization in breeding of eukaryotic microorganisms. Genetika 42: 1571-1576. doi:10 $1134 / \mathrm{s} 1022795406110147$

Pandey SK, Dasgupta T, Rathore A, Vemula A. 2018. Relationship of parental genetic distance with heterosis and specific combining ability in sesame (Sesamum indicum L.) based on phenotypic and molecular marker analysis. Biochem Genet 56: 188-209. doi:10.1007/s10528-017-9837-2

Pâques F, Haber JE. 1999. Multiple pathways of recombination induced by double-strand breaks in Saccharomyces cerevisiae. Microbiol Mol Biol Rev 63: 349-404. doi:10.1128/MMBR.63.2.349-404.1999

Paschold A, Jia Y, Marcon C, Lund S, Larson NB, Yeh CT, Ossowski S, Lanz C, Nettleton D, Schnable PS, et al. 2012. Complementation contributes to transcriptome complexity in maize (Zea mays L.) hybrids relative to their inbred parents. Genome Res 22: 2445-2454. doi:10.1101/gr .138461 .112

Pertea M, Kim D, Pertea GM, Leek JT, Salzberg SL. 2016. Transcript-level expression analysis of RNA-seq experiments with HISAT, StringTie and Ballgown. Nat Protoc 11: $1650-1667$. doi:10.1038/nprot.2016.095

Piper MD, Hong SP, Ball GE, Dawes IW. 2000. Regulation of the balance of one-carbon metabolism in Saccharomyces cerevisiae. J Biol Chem 275: 30987-30995. doi:10.1074/jbc.M004248200

Plech M, de Visser J, Korona R. 2014. Heterosis is prevalent among domesticated but not wild strains of Saccharomyces cerevisiae. G3 (Bethesda) 4: 315-323. doi:10.1534/g3.113.009381

Pontes A, Čadež N, Gonçalves P, Sampaio JP. 2019. A quasi-domesticate relic hybrid population of Saccharomyces cerevisiae $\times S$. paradoxus adapted to olive brine. Front Genet 10: 449. doi:10.3389/fgene.2019.00449

Powers L. 1944. An expansion of Jones's theory for the explanation of heterosis. Am Nat 78: 275-280. doi:10.1086/281199
Rapp RA, Udall JA, Wendel JF. 2009. Genomic expression dominance in allopolyploids. BMC Biol 7: 18. doi:10.1186/1741-7007-7-18

R Core Team. 2016. R: a language and environment for statistical computing. $\mathrm{R}$ Foundation for Statistical Computing, Vienna. https://www.R-project .org/.

Richey FD. 1942. Mock-dominance and hybrid vigor. Science 96: 280-281. doi:10.1126/science.96.2490.280

Riddle NC, Jiang HM, An LL, Doerge RW, Birchler JA. 2010. Gene expression analysis at the intersection of ploidy and hybridity in maize. Theor Appl Genet 120: 341-353, doi:10.1007/s00122-009-1113-3

Rosenzweig A, Blenis J, Gomes AP. 2018. Beyond the Warburg effect: How do cancer cells regulate one-carbon metabolism? Front Cell Dev Biol 6: 90. doi:10.3389/fcell.2018.00090

Schaefke B, Emerson JJ, Wang TY, Lu MYJ, Hsieh LC, Li WH. 2013. Inheritance of gene expression level and selective constraints on transand cis-regulatory changes in yeast. Mol Biol Evol 30: 2121-2133. doi:10.1093/molbev/mst114

Schnable PS, Springer NM. 2013. Progress toward understanding heterosis in crop plants. Annu Rev Plant Biol 64: 71-88. doi:10.1146/annurevarplant-042110-103827

Shapira R, David L. 2016. Genes with a combination of over-dominant and epistatic effects underlie heterosis in growth of Saccharomyces cerevisiae at high temperature. Front Genet 7: 14. doi:10.3389/fgene.2016.00072

Shapira R, Levy T, Shaked S, Fridman E, David L. 2014. Extensive heterosis in growth of yeast hybrids is explained by a combination of genetic models. Heredity (Edinb) 113: 316-326. doi:10.1038/hdy.2014.33

Shull GH. 1908. The composition of a field of maize. J Hered os-4: 296-301. doi:10.1093/jhered/os-4.1.296

Shull GH. 1911. The genotypes of maize. Am Nat 45: 234-252. doi:10.1086/ 279207

Shull GH. 1914. Duplicate genes for capsule form in Bursa bursa pastoris. Mol Gen Genet 12: 97-149. doi:10.1007/BF01837282

Sinha H, Nicholson BP, Steinmetz LM, McCusker JH. 2006. Complex genetic interactions in a quantitative trait locus. PLoS Genet 2: e13. doi:10 .1371/journal.pgen.0020013

Steinmetz LM, Sinha H, Richards DR, Spiegelman JI, Oefner PJ, McCusker JH, Davis RW. 2002. Dissecting the architecture of a quantitative trait locus in yeast. Nature 416: 326-330. doi:10.1038/416326a

Stupar RM, Gardiner JM, Oldre AG, Haun WJ, Chandler VL, Springer NM. 2008. Gene expression analyses in maize inbreds and hybrids with varying levels of heterosis. BMC Plant Biol 8: 33. doi:10.1186/1471-2229-833

Tian MZ, Nie O Li ZH, Zhang JL, Liu YL, Long Y, Wang ZW, Wang GQ Liu RX. 2018. Transcriptomic analysis reveals overdominance playing a critical role in nicotine heterosis in Nicotiana tabacum L. BMC Plant Biol 18: 48. doi:10.1186/s12870-018-1257-x

Timberlake WE, Frizzell MA, Richards KD, Gardner RC. 2011. A new yeast genetic resource for analysis and breeding. Yeast 28: $63-80$. doi:10 $.1002 /$ yea. 1821

Topf U, Suppanz I, Samluk L, Wrobel L, Böser A, Sakowska P, Knapp B, Pietrzyk MK, Chacinska A, Warscheid B. 2018. Quantitative proteomics identifies redox switches for global translation modulation by mitochondrially produced reactive oxygen species. Nat Commun 9: 17 . doi:10.1038/s41467-017-02694-8

Torres EM, Sokolsky T, Tucker CM, Chan LY, Boselli M, Dunham MJ, Amon A. 2007. Effects of aneuploidy on cellular physiology and cell division in haploid yeast. Science 317: 916-924. doi:10.1126/science. 1142210

Tsai HJ, Nelliat A. 2019. A double-edged sword: aneuploidy is a prevalent strategy in fungal adaptation. Genes (Basel) 10: 787. doi:10.3390/ genes 10100787

Vasseur F, Fouqueau L, de Vienne D, Nidelet T, Violle C, Weigel D. 2019. Nonlinear phenotypic variation uncovers the emergence of heterosis in Arabidopsis thaliana. PLoS Biol 17: e3000214. doi:10.1371/journal pbio.3000214

Wang Q-M, Liu W-Q, Liti G, Wang S-A, Bai F-Y. 2012. Surprisingly diverged populations of Saccharomyces cerevisiae in natural environments remote from human activity. Mol Ecol 21: 5404-5417. doi:10.1111/j.1365294X.2012.05732.x

Warringer J, Blomberg A. 2003. Automated screening in environmental arrays allows analysis of quantitative phenotypic profiles in Saccharomyces cerevisiae. Yeast 20: $53-67$. doi:10.1002/yea.931

Wei XZ, Zhang JZ. 2018. The optimal mating distance resulting from heterosis and genetic incompatibility. Sci Adv 4: 7. doi:10.1126/sciadv aau5518

Wei G, Tao Y, Liu GZ, Chen C, Luo RY, Xia HA, Gan Q, Zeng HP, Lu ZK, Han YN, et al. 2009. A transcriptomic analysis of superhybrid rice $L Y P 9$ and its parents. Proc Natl Acad Sci 106: 7695-7701. doi:10.1073/pnas .0902340106

Yu SB, Li JX, Xu CG, Tan YF, Gao YJ, Li XH, Zhang Q, Saghai Maroof MA. 1997. Importance of epistasis as the genetic basis of heterosis in an elite 
Song et al.

rice hybrid. Proc Natl Acad Sci 94: 9226-9231. doi:10.1073/pnas.94.17 .9226

Zafarullah M, Li WQ, Sylvester J, Ahmad M. 2003. Molecular mechanisms of $\mathrm{N}$-acetylcysteine actions. Cell Mol Life Sci 60: 6-20. doi:10.1007/ s000180300001

Zhang J, Sonnenschein N, Pihl TPB, Pedersen KR, Jensen MK, Keasling JD. 2016. Engineering an NADPH/NADP ${ }^{+}$redox biosensor in yeast. ACS Synth Biol 5: 1546-1556. doi:10.1021/acssynbio.6b00135

Zhao Y, Hu FX, Zhang XG, Wei QY, Dong JL, Bo C, Cheng BJ, Ma Q. 2019. Comparative transcriptome analysis reveals important roles of nonadditive genes in maize hybrid An'nong 591 under heat stress. BMC Plant Biol 19: 273. doi:10.1186/s12870-019-1878-8
Zhou YY, Zhou B, Pache L, Chang M, Khodabakhshi AH, Tanaseichuk O, Benner C, Chanda SK. 2019. Metascape provides a biologist-oriented resource for the analysis of systems-level datasets. Nat Commun 10: 1523. doi:10.1038/s41467-019-09234-6

Zörgö E, Gjuvsland A, Cubillos FA, Louis EJ, Liti G, Blomberg A, Omholt SW, Warringer J. 2012. Life history shapes trait heredity by accumulation of loss-of-function alleles in yeast. Mol Biol Evol 29: 1781-1789. doi:10 $.1093 / \mathrm{molbev} / \mathrm{mss} 019$

Received February 6, 2020; accepted in revised form February 12, 2021.

\section{Genome Research}

www.genome.org 


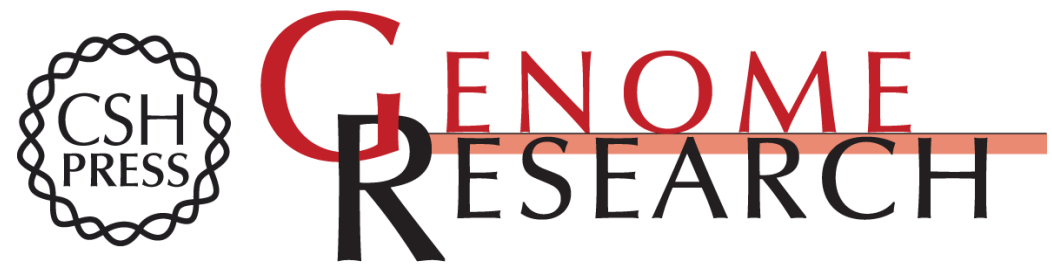

\title{
Improved redox homeostasis owing to the up-regulation of one-carbon metabolism and related pathways is crucial for yeast heterosis at high temperature
}

\author{
Liang Song, Jun-Yan Shi, Shou-Fu Duan, et al.
}

Genome Res. 2021 31: 622-634 originally published online March 15, 2021

Access the most recent version at doi:10.1101/gr.262055.120

\section{Supplemental http://genome.cshlp.org/content/suppl/2021/03/15/gr.262055.120.DC1 \\ Material \\ References This article cites 98 articles, 21 of which can be accessed free at: \\ http://genome.cshlp.org/content/31/4/622.full.html\#ref-list-1 \\ Creative This article is distributed exclusively by Cold Spring Harbor Laboratory Press for the Commons first six months after the full-issue publication date (see \\ License https://genome.cshlp.org/site/misc/terms.xhtml). After six months, it is available under a Creative Commons License (Attribution-NonCommercial 4.0 International), as described at http://creativecommons.org/licenses/by-nc/4.0/.} Email Alerting $\begin{aligned} & \text { Receive free email alerts when new articles cite this article - sign up in the box at the } \\ & \text { Service }\end{aligned}$ top right corner of the article or click here.

\section{Affordable, Accurate Sequencing.}

To subscribe to Genome Research go to:

https://genome.cshlp.org/subscriptions

(C) 2021 Song et al.; Published by Cold Spring Harbor Laboratory Press 